\title{
Antioxidant Activity Determination of Citronellal and Crude Extracts of Cymbopogon citratus by 3 Different Methods
}

\author{
Y. Lu*, T. J. Khoo, C. Wiart \\ School of Pharmacy, Faculty of Science, University of Nottingham, Malaysia Campus, Semenyih, Selongar, \\ Malaysia \\ Email: emilyly@126.com, khyx2lyo@nottingham.edu.my
}

Received 24 January 2014; revised 19 March 2014; accepted 4 April 2014

Copyright (C) 2014 by authors and Scientific Research Publishing Inc.

This work is licensed under the Creative Commons Attribution International License (CC BY). http://creativecommons.org/licenses/by/4.0/

(c) (i) Open Access

\begin{abstract}
Cymbopogon citratus, better known as lemongrass, is a plant commonly used for culinary purposes. It is known to contain the compound citronellal, which is responsible for the lemon-scent of many of the plants of the genus Cymbopogon. A chloroform extract of Cymbopogon citratus was screened to determine its free radical scavenging activities. Three different methods were used to test the antioxidant activity of the extract, including FRAP assay (Ferric reducing antioxidant potential), DPPH radical scavenging assay (1,1-diphenyl-2-picryl hydrazyl radical reducing power methods), and $\beta$-carotene bleaching assay. Cymbopogon citratus showed low radical scavenging activities compared to ascorbic acid, gallic acid and quercetin. The results obtained suggest that Cymbopogon citratus is best appreciated for its refreshing aroma and delicate taste, but has little to offer as a source of antioxidants.
\end{abstract}

\section{Keywords}

Antioxidant Activity; DPPH Assay; FRAP Assay; $\beta$-Carotene Bleaching Assay; Citronellal

\section{Introduction}

Plants of the genus Cymbopogon are commonly used in Asian cooking and the essential oils are valued for their aromatic properties. Citronellal is one of the compounds responsible for the aroma associated with Cymbopogon and is known for its ability to repel insects [1]. The present study aims to determine the antioxidant activity of citronellal and a crude extract of Cymbopogon citratus using in vitro techniques which have been developed to

*Corresponding author. 
test this, including FRAP, DPPH and $\beta$-carotene bleaching assay. Several methods are performed to accurately estimate the antioxidant potential of a sample as it should cover the mechanisms of different reactions [2]. Citronellal and an extract of Cymbopogon citratus were analysed using three different assays to accommodate different antioxidant mechanisms.

Phenolics are composed of one or more aromatic rings bearing one or more hydroxyl groups and are therefore potentially able to quench free radicals by forming stabilized phenoxyl radicals [3] and most of the current antioxidants isolated so far from flowering plants are simple phenolic compounds which owe their properties to the mere fact that their aromatic hydroxyl moieties react with free radicals.

As a part of an ongoing study to identify antioxidants from medicinal plants, we seek to examine the antioxidant potencies and principle of the Malaysian medicinal plant Cymbopogon citratus, previously extracted with chloroform.

\section{Materials and Methods}

\subsection{Plant Material}

The aerial part of Cymbopogon citratus was collected from one individual plant in August 2012 from Bukit Putih, Selongar, Malaysia $\left(3^{\circ} 5^{\prime} 24^{\prime \prime N}, 101^{\circ} 46^{\prime} 0 " \mathrm{E}\right)$. The aerial part was air dried and ground into a fine powder using a medicinal grinder.

\subsection{Chemicals and Reagents}

1,1-Diphenyl-2-picrylhydrazyl (DPPH), 2,4,6-Tris (2-pyridyl)-1,3,5-triazine (TPTZ), citronellal and $\beta$-carotene were purchased from Sigma Aldrich. Quercetin was purchased from Sigma, Germany. Gallic acid was purchased from Tokyo Chemical Industry, Japan. Sodium chloride, ascorbic acid, ferric chloride, and ferrous sulphate were purchased from System. Acetic acid, DMSO, sulfuric acid and hydrochloric acid were purchased from R \& M Marketing, Essex UK. Chloroform, methanol and ethanol were purchased from MERCK. All the chemicals were of analytical grade.

\subsection{Extraction}

Dried and ground samples of the aerial part of the plant $(90 \mathrm{~g})$ were soaked in chloroform in the ratio of 1: 3 for 72 hours, then filtered and concentrated with a rotary evaporator (Buchi, R-200 Switzerland). This was repeated 3 times. The yield of the chloroform extracts of aerial parts was $1.9 \%$. The crude extracts were kept at $-20^{\circ} \mathrm{C}$ until further use.

\subsection{Ferric Reducing Antioxidant Potential Assay (FRAP Assay)}

The antioxidant capacity was determined following the procedure described by Benzie and Strain [4] with modifications. The FRAP reagent was freshly prepared by adding $10 \mathrm{mM}$ of 2,4,6-Tris (2-pyridyl)-1,3,5-triazine (TPTZ) (dissolved in $40 \mathrm{mM}$ of $\mathrm{HCl}$ ), $20 \mathrm{mM}$ of $\mathrm{FeCl}_{3}$ in water and $300 \mathrm{mM}$ of acetate buffer (pH 3.6) in the ratio of 1:1:10. A blank containing sample and solvents only was used for colour correction. The 96-well plates were then incubated at $37^{\circ} \mathrm{C}$ for 90 minutes before absorbance was recorded at $600 \mathrm{~nm}$. Vitamin C (L-ascorbic acid), gallic acid and quercetin were used as antioxidant standards and positive controls. The absorbance of the samples were compared to a $\mathrm{FeSO}_{4}$ standard curve and the FRAP values were expressed as Ferrous Equivalent (FE), the concentration of extract or chemical which gives the same absorbance as $1 \mathrm{mmol}$ ferrous ion.

\subsection{DPPH Radical Scavenging Assay (DPPH Assay)}

The DPPH assay, as previously reported by Alothman et al. [5], was employed to determine the radical scavenging activity of the extracts. Aliquots of extract dissolved in dimethyl sulfoxide (DMSO) were plated out in triplicate in a 96-well microtiter plate. The methanolic DPPH $(50 \mu \mathrm{M})$ solution (Aldrich) was added to alternating columns of the test samples and methanol was used for control of test samples, in the remaining columns. The plate was shaken for 2 minutes and incubated for 20 minutes in darkness at $37^{\circ} \mathrm{C}$, in a water bath. The percentage of decolourisation was obtained spectrophotometrically at $517 \mathrm{~nm}$ using the Thermo Scientific Varioskan Flash microtiter plate reader, linked to a computer equipped with (SkanIt Software 2.4.3). The percentage 
of decolourisation was plotted against the concentration of the sample, and the $\mathrm{EC}_{50}$ values were determined using Prism 5.00 software. Vitamin C (L-ascorbic acid), gallic acid and quercetin were used as antioxidant standards and positive controls. At least three independent tests were performed for each sample. The DPPH absorbance decreases with an increase in DPPH radical scavenging activity. Results were expressed as $\mathrm{IC}_{50}$ concentration where $50 \%$ inhibition of the DPPH radical is obtained. This activity is given as the percent of DPPH radical scavenged, which is calculated with the equation:

$$
\text { DPPH radical scavenging activity }(\%)=\left[\left(A b s_{\text {control }}-A b s_{\text {sample }}\right) /\left(A b s_{\text {control }}\right)\right] \times 100
$$

where $A b s_{\text {control }}$ is the absorbance of DPPH radical + methanol and $A b s_{\text {sample }}$ is absorbance DPPH radical + sample extract/standard.

\section{6. $\beta$-Carotene Bleaching Assay}

To assess lipid peroxidation activity of the samples, $\beta$-carotene bleaching assay was carried out according to the method described by Barreira et al. [6]. $\beta$-carotene was dissolved in chloroform, and linoleic acid and Tween 80 were added. After the chloroform had evaporated, distilled water was added to form an emulsion. The emulsion was tested with different concentrations of the sample and standards. Incubation was done at $50^{\circ} \mathrm{C}$ for 4 hours. The oxidation of the $\beta$-carotene emulsion was monitored by measuring the absorbance at $490 \mathrm{~nm}$ via a Dynex microplate reader. Degradation rates were calculated according to first order kinetics. The activity is calculated with the equations below:

$$
\text { Degradation rate }(D R)=\ln a / b \times 1 / t
$$

where " $a$ " is the initial absorbance, " $b$ " is the absorbance at $240 \mathrm{~min}$ and " $t$ " is the total test time (240 min).

The antioxidant activity was presented as percent of inhibition using the following formula:

$$
\text { Antioxidant activity }(\%)=(D R \text { control }-D R \text { sample }) / D R \text { control } \times 100 \text {. }
$$

$\mathrm{IC}_{50}$ : concentration where $50 \%$ inhibition of the $\beta$-carotene bleaching radical is obtained.

\section{Results and Discussion}

\subsection{Ferric Reducing Antioxidant Potential Assay (FRAP Assay)}

The FRAP assay was employed to estimate the antioxidant capacity of the samples in vitro. In this test, the result (Figure 1) revealed that a good linearity of ferrous sulfate $\left(\mathrm{FeSO}_{4}\right)$ was obtained within the range of 0.15 - 1.40 $\mathrm{mM}\left(\mathrm{R}^{2}=0.9999\right)$. The antioxidant activities were highest for quercetin (Table 1) $(5.56 \pm 0.002 \mathrm{mmol} / \mathrm{g})$, followed by ascorbic acid $(4.79 \pm 0.002 \mathrm{mmol} / \mathrm{g})$, gallic acid $(2.17 \pm 0.002 \mathrm{mmol} / \mathrm{g})$, citronella $(1.03 \pm 0.002$ $\mathrm{mmol} / \mathrm{g})$ and lastly Cymbopogon citratus, with the lowest antioxidant activity $(0.09 \pm 0.002 \mathrm{mmol} / \mathrm{g})$.

\subsection{DPPH Radical Scavenging Assay (DPPH Assay)}

In the DPPH radical scavenging assay, antioxidants react with DPPH, and convert it to the yellow coloured a, a-diphenyl- $\beta$-picryl hydrazine. The degree of discolouration indicates the radical-scavenging potential of the sample [7]. In this test, the Cymbopogon citratus extract exhibited little antioxidant activity (Table 2 and Table 3; Figure 2). The antioxidant activities were highest for ascorbic acid (IC ${ }_{50}: 0.60 \pm 0.01 \mu \mathrm{g} / \mathrm{mL}$ ), followed by quercetin ( $\mathrm{IC}_{50}: 1.00 \pm 0.01 \mu \mathrm{g} / \mathrm{mL}$ ), gallic acid $\left(\mathrm{IC}_{50}: 1.50 \pm 0.02 \mu \mathrm{g} / \mathrm{mL}\right.$ ), citronellal ( $\mathrm{IC}_{50}: 79.90 \pm 0.02 \mu \mathrm{g} / \mathrm{mL}$ ) and lastly Cymbopogon citratus ( $\mathrm{IC}_{50}: 1998.10 \pm 0.02 \mu \mathrm{g} / \mathrm{mL}$ ) (Table 2 and Table 3; Figure 2).

\section{3. $\beta$-Carotene Bleaching Assay}

The $\beta$-carotene bleaching method is based on the loss of the yellow colour of b-carotene due to its reaction with radicals which are formed by linoleic acid oxidation in an emulsion. The rate of $\beta$-carotene bleaching can be slowed down in the presence of antioxidants. This fact is used in the evaluation of the antioxidant activity of the sample in comparison with ascorbic acid (vitamin C), gallic acid and quercetin. In this assay, the antioxidant activities were highest for ascorbic acid ( $\mathrm{IC}_{50}: 9.60 \pm 0.01 \mu \mathrm{g} / \mathrm{mL}$ ), followed by gallic acid $\left(\mathrm{IC}_{50}: 10.50 \pm 0.02\right.$ $\mu \mathrm{g} / \mathrm{mL}$ ), quercetin ( $\mathrm{IC}_{50}: 25.10 \pm 0.01 \mu \mathrm{g} / \mathrm{mL}$ ), citronellal ( $\mathrm{IC}_{50}: 48.70 \pm 0.02 \mu \mathrm{g} / \mathrm{mL}$ ) and Cymbopogon citratus ( $\mathrm{IC}_{50}: 95.90 \pm 0.02 \mu \mathrm{g} / \mathrm{mL}$ ) (Table 4). 


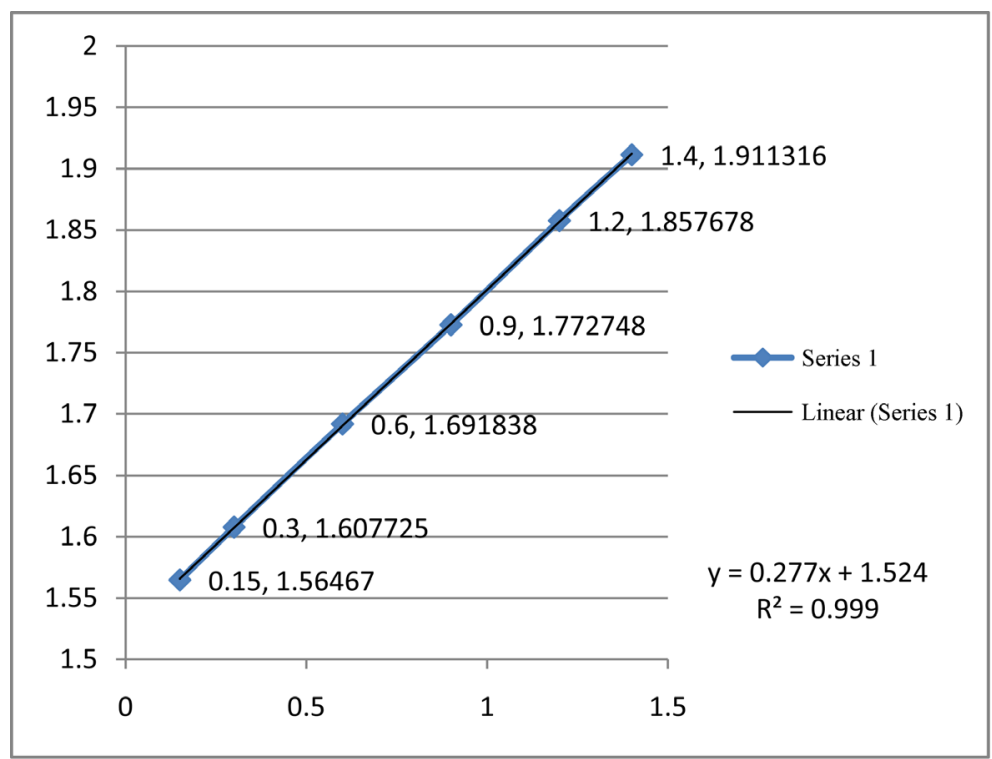

Figure 1. $\mathrm{FeSO}_{4}$ standard curve. Standard equation: $\mathrm{y}=0.2771 \mathrm{x}+1.5242 ; \mathrm{R}^{2}$ $=0.9999$.

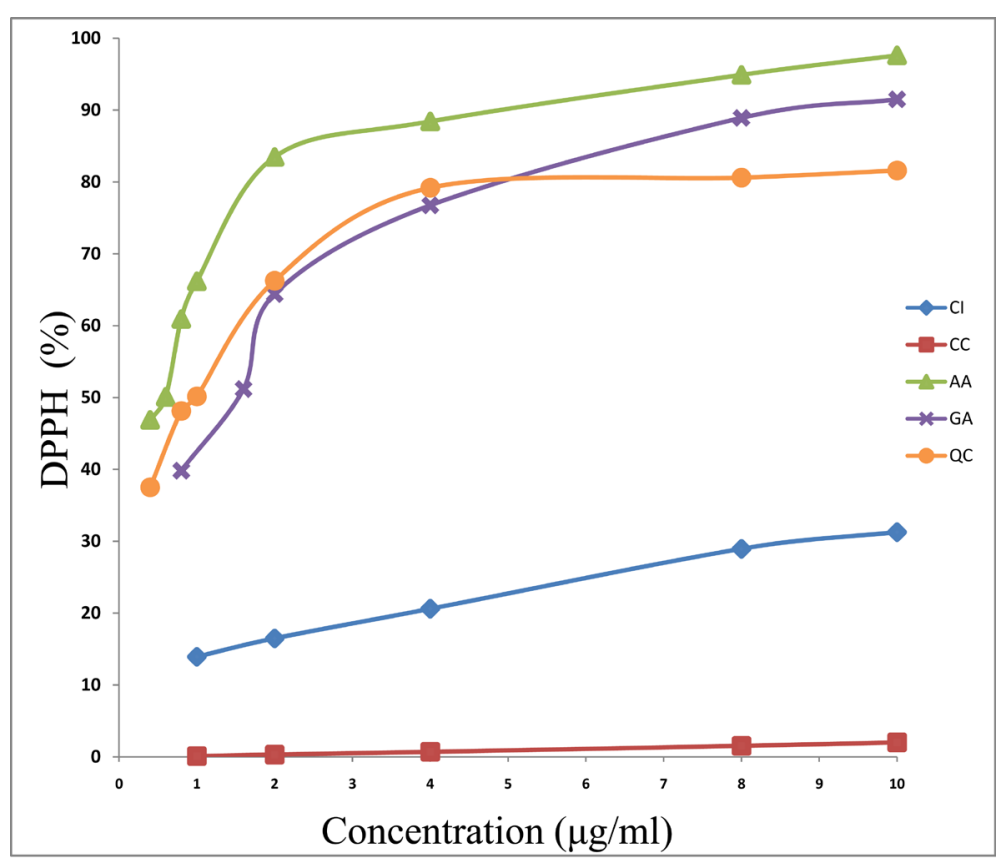

Figure 2. DPPH radical scavenging activity (\%) versus concentration $(\mu \mathrm{g} / \mathrm{mL})$. CI: Citronellal, CC: Cymbopogon citratus, AA: Ascorbic Acid, GA: Gallic Acid, QC: Quercetin.

\subsection{Discussion}

The FRAP assay was employed to estimate the antioxidant capacity of the samples in vitro. In the DPPH radical scavenging assay, antioxidants react with DPPH, and convert it to the yellow coloured a, a-diphenyl- $\beta$-picryl hydrazine. The degree of discolouration indicates the radical-scavenging potential of the sample. The $\beta$-carotene bleaching method is based on the loss of the yellow colour of b-carotene due to its reaction with radicals which are formed by linoleic acid oxidation in an emulsion. The rate of $\beta$-carotene bleaching can be slowed down in the presence of antioxidants. In this study, three different methods tested on citronellal and the crude extract of 
Table 1. Ferric reducing antioxidant capacity of extract.

\begin{tabular}{cccc}
\hline SAMPLE & Concentration $(\mathrm{mg} / \mathrm{ml})$ & Ferrous Equivalent $(\mathrm{mM})$ & Antioxidant Capacity $(\mathrm{mmol} / \mathrm{g})$ \\
\hline CI & 1.0 & $1.03 \pm 0.002$ & $1.03 \pm 0.002$ \\
CC & 1.0 & $0.09 \pm 0.002$ & $0.09 \pm 0.002$ \\
AA & 0.25 & $1.20 \pm 0.001$ & $4.79 \pm 0.002$ \\
GA & 0.25 & $0.54 \pm 0.001$ & $2.17 \pm 0.002$ \\
QC & 0.25 & $1.39 \pm 0.001$ & $5.56 \pm 0.002$ \\
\hline
\end{tabular}

CI: Citronellal, CC: Cymbopogon citratus, AA: Ascorbic Acid, GA: Gallic Acid, QC: Quercetin.

Table 2. DPPH radical scavenging activity at $10 \mu \mathrm{g} / \mathrm{mL}$ of extract.

\begin{tabular}{cc}
\hline Extracts & \% DPPH Radical Scavenging \\
\hline CI & $31.20 \pm 0.02$ \\
CC & $2.00 \pm 0.01$ \\
AA & $97.60 \pm 0.00$ \\
GA & $91.50 \pm 0.01$ \\
QC & $81.60 \pm 0.01$
\end{tabular}

CI: Citronellal, CC: Cymbopogon citratus, AA: Ascorbic Acid, GA: Gallic Acid, QC: Quercetin.

Table 3. Concentration of extract at DPPH radical scavenging activity 50\% (IC50).

\begin{tabular}{cc}
\hline Extracts & DPPH IC $_{50}(\mu \mathrm{g} / \mathrm{mL})$ \\
\hline CI & $79.90 \pm 0.02$ \\
CC & $1998.10 \pm 0.02$ \\
AA & $0.60 \pm 0.01$ \\
GA & $1.50 \pm 0.02$ \\
QC & $1.00 \pm 0.01$ \\
\hline
\end{tabular}

CI: Citronellal, CC: Cymbopogon citratus, AA: Ascorbic Acid, GA: Gallic Acid, QC: Quercetin and IC50: concentration where 50\% inhibition of the DPPH radical is obtained.

Table 4. Antioxidant activity of extract at 50\% inhibition of $\beta$-carotene (IC50).

\begin{tabular}{cc}
\hline Extracts & $50 \%$ Inhibition of $\beta$-Carotene $\left(\mathrm{IC}_{50}\right)(\mu \mathrm{g} / \mathrm{mL})$ \\
\hline CI & $48.70 \pm 0.02$ \\
CC & $95.90 \pm 0.02$ \\
AA & $9.60 \pm 0.01$ \\
GA & $10.50 \pm 0.02$ \\
QC & $25.10 \pm 0.01$ \\
\hline
\end{tabular}

CI: Citronellal, CC: Cymbopogon citratus, AA: Ascorbic Acid, GA: Gallic Acid, QC: Quercetin.

Cymbopogon citratus, the result showed that citronellal has better antioxidant effect.

\section{Conclusion}

In the present study, results from antioxidant activities reflected by the FRAP, DPPH, and $\beta$-carotene bleaching 
assay have demonstrated that the Cymbopogon citratus extract possesses a relatively low antioxidant activity. Citronellal showed greater antioxidant activity than the chloroform extract of Cymbopogon citratus, which may or may not reflect the concentration of citronellal present in the extract. Both the crude extract and citronellal showed lower antioxidant activity than that of ascorbic acid, gallic acid and quercetin at the concentrations tested.

\section{References}

[1] Trongtokit, Y., Rongsriyam, Y., Komalamisra, N. and Apiwathnasorn, C. (2005) Comparative Repellency of 38 Essential Oils against Mosquito Bites. Phytotherapy Research, 19, 303-309. http://dx.doi.org/10.1002/ptr.1637

[2] Jayaraman, P., Sakharkar, M.K., Lim, C.S., Tang, T.H. and Sakharkar, K.R. (2010) Activity and Interactions of Antibiotic and Phytochemical Combinations against Pseudomonas aeruginosa in Vitro. International Journal of Biological Sciences, 6, 556-568. http://dx.doi.org/10.7150/ijbs.6.556

[3] Kang, M.-H., Lee, M.S., Choi, M.K., Min, K.S. and Shibamoto, T. (2012) Hypoglycemic Activity of Gymnema Sylvestre Extracts on Oxidative Stress and Antioxidant Status in Diabetic Rats. Journal of Agricultural and Food Chemistry, 60, 2517-2524. http://dx.doi.org/10.1021/jf205086b

[4] Benzie, I.F. and Strain, J.J. (1996) The Ferric Reducing Ability of Plasma (FRAP) as a Measure of "Antioxidant Power”: The FRAP Assay. Analytical Biochemistry, 239, 70-76. http://dx.doi.org/10.1006/abio.1996.0292

[5] Alothman, M., Bhat, R. and Karim, A.A. (2009) Antioxidant Capacity and Phenolic Content of Selected Tropical Fruits from Malaysia, Extracted with Different Solvents. Food Chemistry, 115,785-788. http://dx.doi.org/10.1016/j.foodchem.2008.12.005

[6] Barreira, J., Ferreira, I., Oliveira, M. and Pereira, J. (2008) Antioxidant Activities of the Extracts from Chestnut Flower, Leaf, Skins and Fruit. Food Chemistry, 107, 1106-1113. http://dx.doi.org/10.1016/j.foodchem.2007.09.030

[7] Blois, M.S. (1958) Antioxidant Determinations by the Use of a Stable Free Radical. Nature, 181, 1199-1200. http://dx.doi.org/10.1038/1811199a0 